\title{
A Compartmental Pen for Confined Rodent Populations
}

\author{
URZĄDZENIE DO HODOWANIA ZAMKNIETYCH POPULACJI GRYZONI
}

\section{A. SEMB-JOHANSSON \& O. IVERSEN}

\begin{abstract}
Semb-Johansson A. \& Iversen O., 1982: A compartmental pen for confined rodent populations. Acta theriol., 27, 12: 159-160 [With 1 Fig.]

The main principle of the pen is that the floor can be lowered, whereby the whole area is subdivided by partitions into minor compartments for easy handling of the animals.
\end{abstract}

[Department of Biology, University of Oslo, Blindern-Oslo 3, Norway]

The study of confined rodent populations has proved a useful tool in population ecology. Pen size and arrangements have varied according to the specific needs and the species studied. However, a general problem has always been how to collect the confined animals for routine checks with a minimum of disturbance.

We have for more than 10 years studied confined populations of rodents, and for this purpose have constructed a pen system which satisfies the above mentioned requirements and has proved very useful. Our unit is $2 \times 3$ meters. The walls are made of aluminium frames orginally manufactured for trucks, and commercially available. The floor is constructed of heavy wallboard, specially fortified in the corners with aluminium or steel plates. The floor consists of 9 minor squares, but in the normal position forms a flat continuous area (Fig. 1a). When the colony is checked for counting, etc., the floor can be lowered and aluminium partitions will protrude and divide the pen into 9 separate compartments (Fig. 1b). The animals, which are not harmed by this procedure, are trapped in the compartments. They can easily be collected and their position in the pen is noted. After the check up, the floor is raised and the animals can again move around within the whole pen. To attain easy access to all compartments, the observer sits on a small movable bridge which can be wheeled along the pen (Fig. 1b). When not in use, it can be tilted in an upright position (Fig. 1a).

We have for our studies two set-ups of pens. One is of our standard size, i.e. $2 \times 3$ meters. The other is a double pen $2 \times 6$ meters. This larger pen, which is shown in the figures, can be used as a single unit, or can by removable partitions be seperated into smaller sections, e.g. two sections each $2 \times 3$ meters. In this way we can run two parallel experiments with no exchange of individuals or we can, when the partitioning wall is supplied with openings (as seen in the figure), permit animals to move from one pen to another, e.g., between an optimal and a suboptimal area.

The raising and lowering of the floor in our smallest pen is performed by compressed air, whereas the largest pen $(2 \times 6$ meters $)$ is operated by hydraulics originally manufactured for vehicle service stations.

Our units have been in use for more than ten years and have proved very reliable, but special care must be taken when selecting materials for the construction of the unit, in order to prevent the escape of 


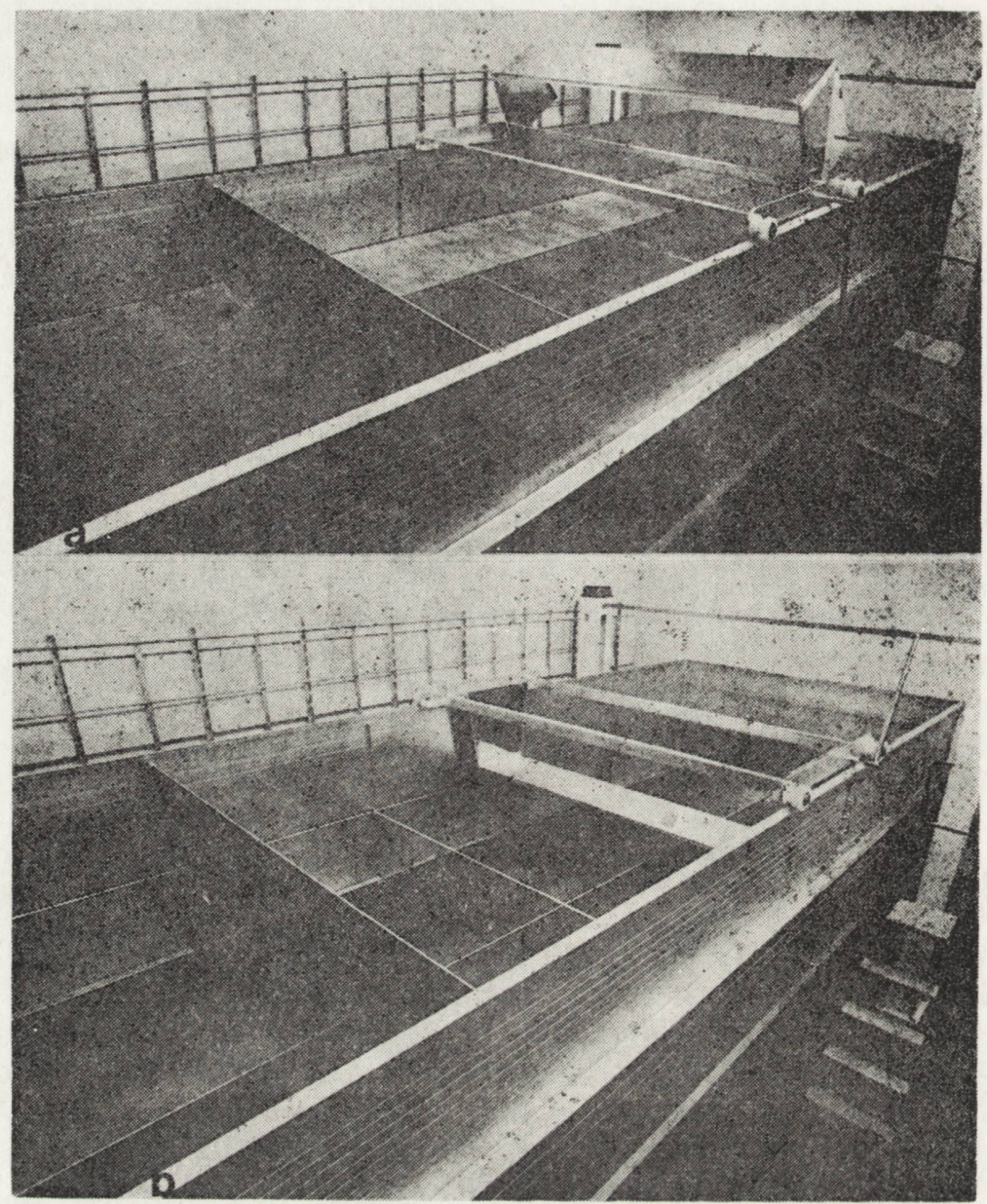

Fig. 1. The upper figure (a) shows the experimental pen ready for use, but without nesting material, food, animals etc. The observation bridge is in an upright position. In fig. $\mathrm{b}$ the floor is lowered and the bridge is tilted down. The arrow points to a whole in the removable partitioning wall.

animals. The units have made possible lengthy detailed studies of populations with the least possible disturbance of the colonies. Results from these studies are published elsewhere (Semb-Johansson et al., 1979)

\section{REFERENCE}

Semb-Johansson A., Wiger R. \& Engh C. E., 1979: Dynamics of freely growing, confined populations of the Norwegian lemming Lemmus lemmus. Oikos, 33: 246-260 .

Accepted, October 20, 1981. 